\title{
Synthesis of 2-Trifluoromethylquinolines via a [2+3] Cycloaddition
}

Gategory

Synthesis of

Heterocycles

Key words

quinolines

trifluoromethyl

group

copper catalysis

ketenimines

[2+3] cycloaddition<smiles>[R7]C(C#C)=Nc1ccccc1</smiles>
$\mathrm{R}^{3} \mathrm{SO}_{2} \mathrm{~N}_{3} \stackrel{\begin{array}{c}\mathrm{CuCl}(10 \mathrm{~mol} \%) \\ \mathrm{K}_{2} \mathrm{CO}_{3} \text { (1.5 equiv) }\end{array}}{\longrightarrow}$ 2 (1.2 equiv) PhMe, r.t., $24 \mathrm{~h}$

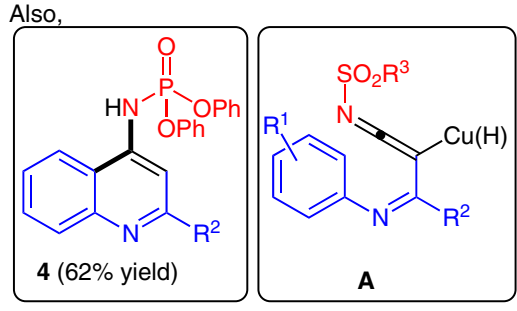

20 examples $21-96 \%$ yield

$\mathrm{R}^{1}=\mathrm{H}, 6-\mathrm{Me}, 6-\mathrm{NMe}_{2}$, 6-Br, 6-I, 6- $\mathrm{CO}_{2} \mathrm{Et}, 5-\mathrm{Cl} / 7-\mathrm{Cl}^{*}$, 5-Me/7-Me ${ }^{*}$, 8-F, 8-Me, 8- $\mathrm{Ph}, 6-\mathrm{OMe}, 7,8-(\mathrm{CH}=\mathrm{CH})_{2}$

$\mathrm{R}^{2}=\mathrm{CF}_{3}$ (16 examples), $\mathrm{C}_{2} \mathrm{~F}_{5}, \mathrm{C}_{3} \mathrm{~F}_{7}, \mathrm{CF}_{2} \mathrm{Cl}_{1} \mathrm{CF}_{2} \mathrm{Br}, \mathrm{CF}_{2} \mathrm{H}$ (trace yield)

$\mathrm{R}^{3}=\mathrm{Ph}, 4^{\prime}-\mathrm{MeC}_{6} \mathrm{H}_{4}, 4^{\prime}-\mathrm{CIC}_{6} \mathrm{H}_{4}, 4^{\prime}-\mathrm{O}_{2} \mathrm{NC}_{6} \mathrm{H}_{4}$

* ratio of regioisomers from $1: 1.7$ to $1: 1.8$

Significance: Reported is the synthesis of 2-trifluoromethyl quinolines $\mathbf{3}$ and $\mathbf{4}$ via a copper-catalyzed Huisgen [2+3]-cycloaddition reaction of sulfonyl azides $\mathbf{2}$ with terminal alkynes $\mathbf{1}$. The starting material 1 was obtained by the reaction of 2,2,2trifluoro- $N$-phenylacetimidoyl chloride with [(trimethylsilyl)ethynyl]magnesium bromide, followed by trimethylsilyl deprotection. Optimum reaction conditions, as presented in the scheme, were used to obtain a variety of quinolines (3). Alkynes $\mathbf{1}$ containing electron-withdrawing groups as $R^{1}$ resulted in poor yield; those with electron-donating groups as $R^{1}$ resulted in moderate to good yields. Compound $\mathbf{3}$ was isolated as a mixture of isomers (C-5/C-7 from 1:1.7 to 1:1.8) when a meta substituent as $R^{1}$ on 1 was used. The method was also extended to the synthesis of 2-perfluoroalkylated quinolines $\left(R^{2}=\mathrm{C}_{2} \mathrm{~F}_{5}, \mathrm{C}_{3} \mathrm{~F}_{7}\right)$ and related analogous $\left(\mathrm{R}^{2}=\mathrm{CF}_{2} \mathrm{Br}, \mathrm{CF}_{2} \mathrm{Cl}\right)$. Use of phosphoryl azide instead of $\mathbf{2}$ under similar conditions resulted in the formation of 4 . A mechanism involving a copper-catalyzed azide-alkyne cycloaddition, followed by the loss of $\mathrm{N}_{2}$ to give intermediate azaallene $\mathbf{A}$, and followed by electrocyclic ring closure to quinolines $\mathbf{3}$ was proposed without experimental evidence.
Comment: The importance of the trifluoromethyl group in drug discovery programs has resulted in the development of new and improved methods for the introduction of $\mathrm{CF}_{3}$ groups onto (hetero)arenes. Although recent focus has been on the transition-metal-mediated cross-couplings and direct $\mathrm{C}-\mathrm{H}$ trifluoromethylations (see Reviews below), methods such as the present one provide competitive alternatives, especially when suitable starting material can be obtained easily. The current method can tolerate a wide range of functional groups, but the yield is lower with electron-poor alkynes. Also, this method was not tested on internal alkynes.

Reviews: X.-F. Wu, H. Neumann, M. Beller Chem. Asian J. 2012, 7, 1744-1754; H. Liu, Z. Gu, X. Jiang Adv. Synth. Catal. 2013, 355, 617-626; T. Besset, C. Schneider, D. Cahard Angew. Chem. Int. Ed. 2012, 51, 5048-5050. 


\section{Gategory}

Synthesis of

Heterocycles

\section{Key words}

\section{1,3-dipolar} cycloaddition

iodine

benzo(f)isoindole4,9-diones

naphthoquinones
H.-M. HUANG, J.-R. GAO, L.-F. HOU, J.-H. JIA, L. HAN, Q. YE, Y.-J. LI* (ZHEJIANG UNIVERSITY OF TECHNOLOGY, HANGZHOU AND ZHENGZHOU UNIVERSITY,

P. R. OF CHINA)

The First Iodine Improved 1,3-Dipolar Cycloaddition: Facile and Novel Synthesis of 2-Substituted

Benzo[f $]$ isoindole-4,9-diones

Tetrahedron 2013, 69, 9033-9037.

\section{lodine-Mediated 1,3-Dipolar Cycloaddition to Benzo(f)isoindole-4,9-diones}

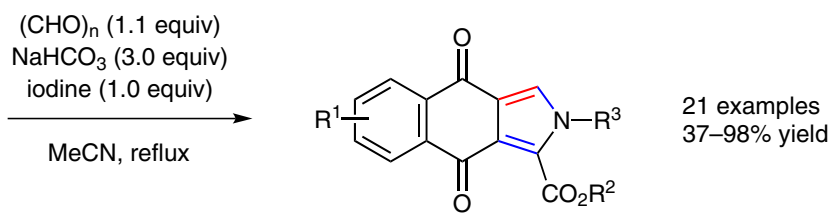

$\mathrm{R}^{1}=\mathrm{H}, 5-\mathrm{HO}, 5-\mathrm{O}_{2} \mathrm{~N}$

$\mathrm{R}^{2}=\mathrm{Et}, n-\operatorname{Pr}, i-\operatorname{Pr}, n-\mathrm{Bu}$, isoamyl

$\mathrm{R}^{3}=\mathrm{Me}, \mathrm{Et}, n-\mathrm{Pr}, n-\mathrm{Bu}, \mathrm{Bn}, \mathrm{Ph}$ (failed)<smiles>O=C1C=CC(=O)c2cc3ccccc3cc21</smiles>

also used as starting material

Significance: Reported is the iodine-mediated synthesis of fused benzo(f)isoindole-4,9-diones through the 1,3-dipolar cycloaddition of naphthoquinones (also anthracene-1,4-dione) with azomethine ylides, the latter being generated in situ from $\mathrm{N}$-alkylated glycine esters and paraformaldehyde. Unfortunately, although the optimization work was performed using a standard reaction time of eight hours, the reaction times of the formation of each of the products in the substrate scope was not given.
Comment: Substituted benzo(f)isoindole-4,9diones are present in many biologically relevant molecules, some examples of which are given in the introduction of the report. The current work provides a rapid and direct method for their synthesis. This method benefits from operational simplicity, no requirement for air-free conditions, and mostly moderate to excellent yields. The reaction was optimized with respect to iodine stoichiometry, solvent, and base. The substrate scope was modestly examined with respect to the glycine ester; moving from ethyl to more sterically bulky esters resulted in lower yields of products.

$\mathrm{N}$-Phenylglycine ethyl ester failed in the reaction, implying that aromatic $\mathrm{N}$-substitution is not tolerated. The substrate scope was poorly examined with respect to the quinone; both 5-hydroxy and 5-nitro naphthoquinones gave almost identical, but modest yields (50\% and 53\%), although anthracene-1,4-dione was capable of furnishing good yields. 


\section{Three-Component Synthesis of (Pyrrolo)quinazolines}

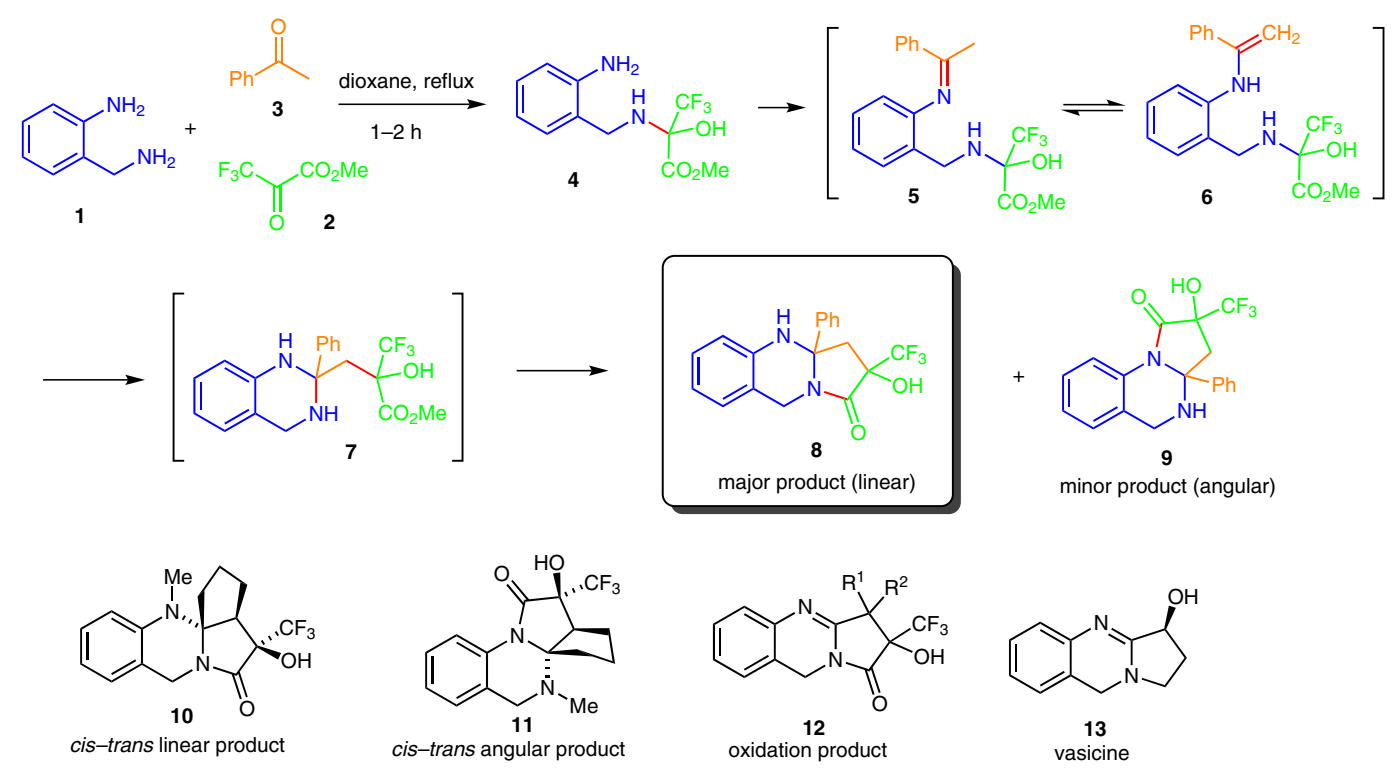

Gategory

Synthesis of

Heterocycles

Key words

three-component

reaction

pyrroloquinazolines

nucleophilic

rearrangement
Significance: By combining three components, 2-aminobenzylamine $\mathbf{1}$, a reactive carbonyl compound (such as trifluoropyruvate) $\mathbf{2}$, and a ketone (or aldehyde) 3, (pyrrolo)quinazolines are formed by a heteroannulation process which involves an interesting rearrangement from 6 to $\mathbf{7}$. A detailed mechanistic study of the process was carried out, providing evidence that the reaction proceeds via the hemiaminal $\mathbf{4}$ and Schiff base $\mathbf{5}$, which is in equilibrium with its enamine $\mathbf{6}$. This step is followed by an unusual intramolecular cyclizationmigration sequence. Alternative lactam ring closure occurs, forming the tricyclic products $\mathbf{8}$ or $\mathbf{9}$. The linearly annulated (pyrrolo)quinazoline 8 (major product) conveniently possess the skeleton of alkaloids of the vasicine group (13). The quinazoline derivatives in general exhibit a variety of biological activities.

sYNFACTS Contributors: Victor Snieckus, Ondřej Kysilka Synfacts 2014, 10(1), 0015 Published online: 13.12.2013 Dol: 10.1055/s-0033-1340415; Reg-No.: V14613SF
Comment: This report builds on previous work by the same authors on the synthesis of (pyrrolo)quinazolines and the reactivity of trifluoropyruvate hemiaminals (Eur. J. Org. Chem. 2013, 1262; J. Fluorine. Chem. 2005, 126, 745). The cyclization proceeds with high regio- and stereoselectivities for the particular carbonyl compounds and is temperature dependent. Complete selectivity of the reaction can be achieved utilizing $N$-monomethylated aminobenzylamine as a starting material, affording exclusively the linear or angular products $\mathbf{1 0}$ or $\mathbf{1 1}$ using cyclopentanone as the starting ketone. Certain linear products can be oxidized by the excess of trifluoropyruvate, forming 12 with complete regioselectivity. The authors unambiguously established the relative configuration on the stereogenic centers utilizing a sophisticated combination of homo- and heteronuclear NOE experiments (Magn. Res. Chem. 2010, 48, 375). 
Synthesis of

Heterocycles

\section{Key words}

phenanthridines

Togni's reagent

radical

trifluoromethylation

isonitriles

Ruppert-Prakash reagent
B. ZHANG, C. MÜCK-LICHTENFELD, C. G. DANiliuC, A. STUDER* (WESTFÄlische WILHELMS-UNIVERSITÄT MÜNSTER, GERMANY)

6-Trifluoromethyl-Phenanthridines through Radical Trifluoromethylation of Isonitriles Angew. Chem. Int. Ed. 2013, 52, 10792-10795.

\section{Synthesis of 6-Trifluoromethyl- Phenanthridines from Diaryl Isonitriles}

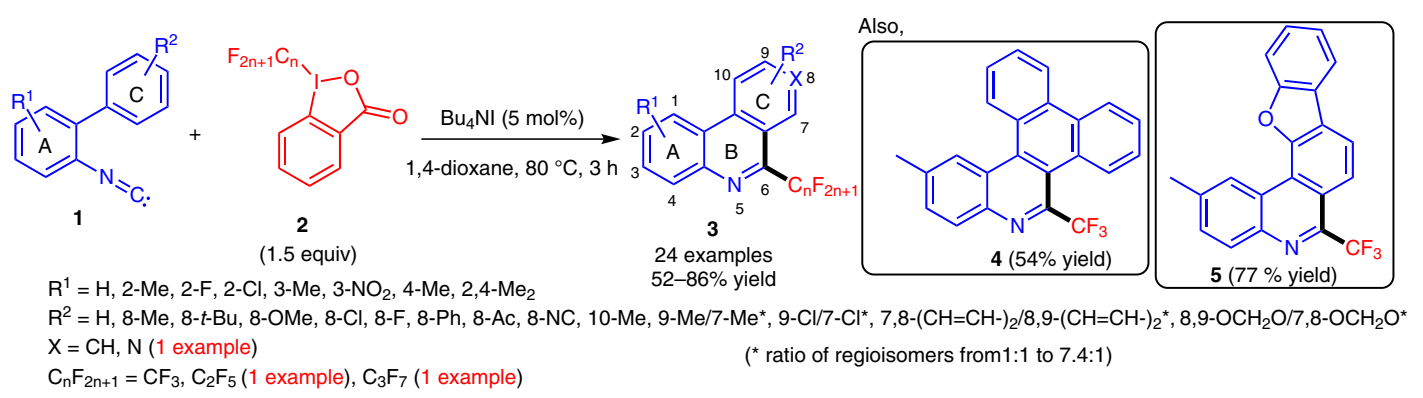

Significance: Reported is the synthesis of 6-trifluoromethyl phenanthridines (3-5) from the reaction of readily available isonitriles $\mathbf{1}$ with the Togni reagent $(\mathbf{2}, \mathrm{n}=\mathbf{1})$ involving a radical trifluoromethylation reaction. Initially, transition metals (salts of copper, iron, nickel, and cobalt) were used to carry out this transformation, but later it was realized that $\mathrm{Bu}_{4} \mathrm{NI}$ can be successfully used as a radical initiator. A range of 6-trifluoromethyl-phenanthridines were obtained in moderate to good yields. For meta-substituted ring- $\mathrm{C}$ derivatives of $\mathbf{1}$, cyclization preferably occurred at the position distal to the meta substituent, but regiocontrol was low (1:1 to $7.4: 1)$. The method was also applied to the synthesis of 6-perfluoroalkylated phenanthridines $\left(\mathrm{C}_{n} \mathrm{~F}_{2 n+1}, \mathrm{n}=2\right.$, 3). The reaction did not proceed in the presence of TEMPO, suggesting a radical mechanism involving the addition of $\mathrm{CF}_{3}$ radical to the isonitrile group, followed by a cyclization event.

Reviews: X.-F. Wu, H. Neumann, M. Beller Chem. Asian J. 2012, 7, 1744-1754; H. Liu, Z. Gu, X. Jiang Adv. Synth. Catal. 2013, 355, 617-626; T. Besset, C. Schneider, D. Cahard Angew. Chem. Int. Ed. 2012, 51, 5048-5050.
Comment: Trifluoromethylated (hetero)arenes are important structural motifs for drug discovery programs. Classic methods for the synthesis of $\mathrm{CF}_{3^{-}}$ substituted (hetero)arenes rely mostly on the commercial availability of $\mathrm{CF}_{3}$-bearing starting materials usually obtained by industrially unviable Swartstype reactions (G. K. S. Prakash, J. Hu, J. Simon, D. R. Bellew, G. A. Olah J. Fluorine Chem. 2004, 125, 595). In more recent developments, the $\mathrm{CF}_{3}$ group has been introduced by transition-metalmediated cross-coupling reactions or direct $\mathrm{C}-\mathrm{H}$ trifluoromethylation (see Reviews below). Despite some modest improvement in this field, new routes for the high-yielding and site-selective introduction of $\mathrm{CF}_{3}$ groups on (hetero)arenes are required. The present method utilizes readily prepared isonitriles and provides 6-perfluoroalkylated phenanthridines without transition-metal-based catalysis. However, the Togni reagent is potentially explosive and should be handled with care (N. Fiederling, J. Haller, H. Schramm Org. Process Res. Dev. 2013, 17, 318). Conceptually, this method is similar to Zhou's approach (Q. Wang, X. Dong, T. Xiao, L. Zhou Org. Lett. 2013, 15, 4846) in which, instead of the Togni reagent, a combination of $\mathrm{Phl}(\mathrm{OAc})_{2}$ and the Ruppert-Prakash reagent $\left(\mathrm{TMSCF}_{3}\right)$ was used at room temperature to obtain similar derivatives. 


\section{Synthesis of Fused Imidazole-Chromenone and -Quinolone Derivatives}

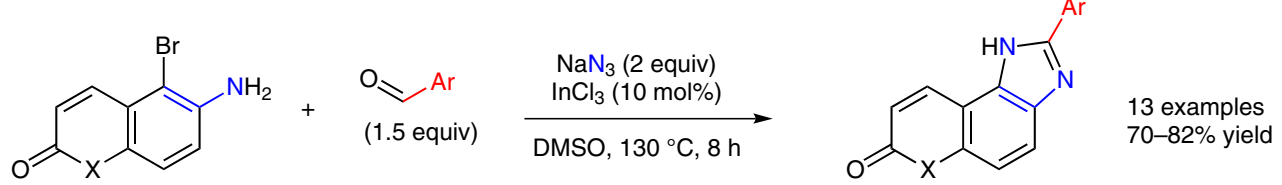

Significance: Reported is the indium chloride catalyzed synthesis of fused chromenone- and quinolone-imidazole systems by the reaction of aromatic 2-amino bromides with sodium azide. The reaction benefits from operational simplicity, reasonable reaction times, and good yields. In addition, it also enjoys the usual benefits of multicomponent reactions, such as good atom economy and reduced reaction times over a linear sequence. Although two mechanisms are proposed, no evidence of mechanism or potential intermediates is provided.

Book: R. D. Larsen, In Science of Synthesis, Vol. 15; D. StC. Black, Ed.; Georg Thieme Verlag: Stuttgart, New York, 2005, 551-660.
Comment: The imidazole structure is often utilized in medicinal chemistry as a drug-design strategy due to its association with a variety of biological activities, as outlined in the introduction to the current report. Likewise, chromenones and quinolones are components of a large number of biologically active compounds and there are a variety of methods for their synthesis (see Book below). The current work provides a method for the fusion of these two important ring systems. The reaction was optimized with respect to catalyst (reaction failed in the absence of catalyst), catalyst loading, solvent, and temperature. The use of indium(III) chloride proved decisive in achieving good yields, as the copper catalysts used in similar work (Y. Kim, M. R. Kumar, N. Park, Y. Heo, S. Lee J. Org. Chem. 2011, 76, 9577) gave only modest yield. The substrate scope of the reaction was modestly studied with respect to the aromatic aldehyde and demonstrated that electron-rich aldehydes provided good yields, but those with electron-withdrawing groups gave only complex mixtures of products. The reaction was unsuitable for aliphatic aldehydes. 
Synthesis of

Heterocycles

\section{Key words}

ruthenium catalysis

indoles

C-H functionalization

B. LI, * J. MA, W. XIE, H. SONG, S. XU, B. WANG* (NANKAI UNIVERSITY, TIANJIN AND SHANGHAI INSTITUTE OF ORGANIC CHEMISTRY, P. R. OF CHINA)

Ruthenium-Catalyzed Regioselective C2 Alkenylation of Indoles and Pyrroles via C-H Bond Functionalization J. Org. Chem. 2013, 78, 9345-9353.

\section{C2-Substituted Indoles via Ruthenium- Catalyzed C-H Bond Functionalization}

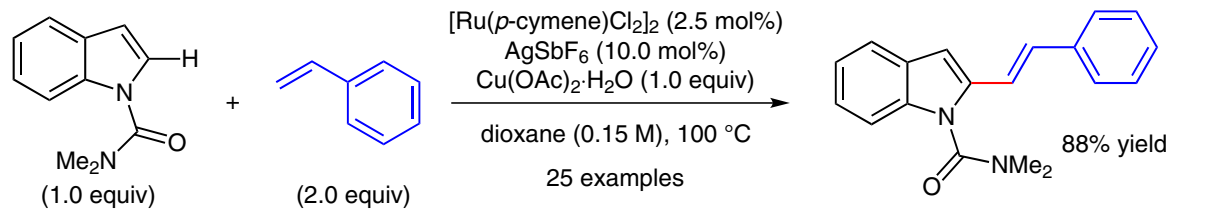

Representative examples:
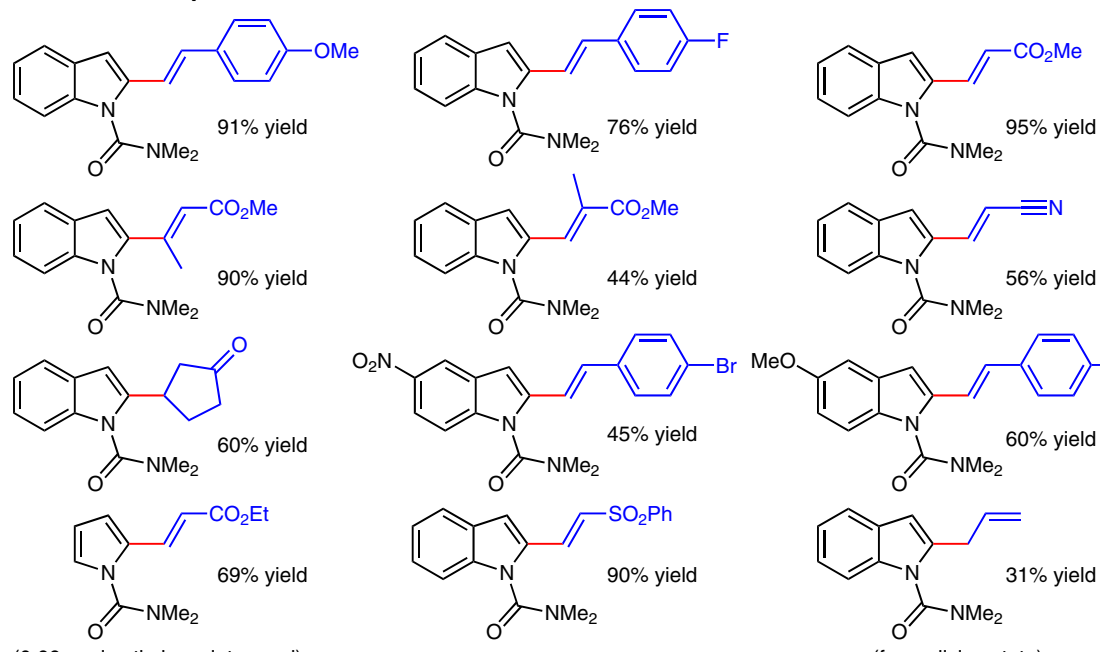

( 0.66 equiv ethyl acrylate used)<smiles>CC(=O)OC(C)=Cc1cc2ccccc2n1C(=O)N(C)C</smiles><smiles>CC(=O)n1c(/C=C/C#N)cc2ccccc21</smiles><smiles>C=CCc1cc2ccccc2n1C(=O)n1c(/C=C/c2ccc(Br)cc2)cc2cc(OC)ccc21</smiles>

Significance: A ruthenium-catalyzed method for the oxidative alkenylation of indoles which utilizes an $\mathrm{N}, \mathrm{N}$-dimethylcarbamoyl group to direct $\mathrm{C}-\mathrm{H}$ functionalization is described. While several examples of ruthenium-catalyzed C2 alkenylation of indoles are known, in one case the scope of the coupling partners was limited to acrylates (V. Lanke, K. R. Prabhu Org. Lett. 2013, 15, 2818). In contrast, the substrate scope of the present report includes both electron-rich and -deficient styrenes, acylates, substituted acrylates, acrylonitrile, a vinyl sulfone, and cyclopentenone. A closely related method that utilizes oxygen as the terminal oxidant was recently reported (L.-Q. Zhang, S. Yang, X. Huang, J. You, F. Song Chem. Commun. 2013, 49, 8830).

SYNFACTS Contributors: Victor Snieckus, Matthew S. Dowling (Pfizer) Synfacts 2014, 10(1), 0018 Published online: 13.12.2013 Dol: 10.1055/s-0033-1340428; Reg-No.: V15913SF
Comment: Due to their inherent electronic character, indoles normally undergo electrophilic substitution reaction at C3. However, multiple methods exist for C2 indole functionalization including directed ortho metalation (DoM) as well as creative palladium-, rhodium-, and ruthenium-based methods from the Gaunt, Ricci, Song, and Arrayás groups. The notable features of the present report include: 1. The observation that electron-rich indoles and/or electron-rich styrenes undergo reaction faster than their electron-deficient counterparts in competition experiments; 2. Pyrroles were identified as viable reaction partners in this chemistry; 3. Disubstituted alkenes, which can be challenging substrates for intermolecular Heck reactions, were shown to be viable. Attempted isolation of the putative ruthenium(II)-cyclometalated intermediate was not successful. 


\section{Synthesis of 1,2,3-Triazoles from $\mathrm{N}$-Tosylhydrazones and Anilines}

Category

Synthesis of

Heterocycles

Key words

1,2,3-triazoles

N-tosylhydrazones

anilines

regioselectivity

copper catalysis
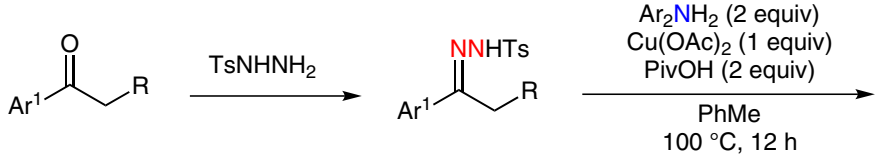

$\left.\mathrm{Ar}^{2}\right|_{\mathrm{Ar}{ }^{1}} ^{N-N}$

61 examples $31-90 \%$ yield

$\mathrm{R}^{1}: \mathrm{R}^{1}=\mathrm{H}, 4-\mathrm{Me}$, 3-Me, 2-Me, 2,4-Me 2 , 3,4-Me 2 , 4-OMe, 3-OMe, 2-OMe, 3,4-(OMe $)_{2}$, 4-Et, 4-i-Pr, 4-n-Bu, $\operatorname{Ar}^{1}=$<smiles>CC(C)(C)c1ccc2c(C(C)(C)C)cccc2c1</smiles><smiles>Cc1ccc2c(c1)Cc1ccccc1-2</smiles><smiles>[Y][Y]([CH])(C)c1ccoc1</smiles><smiles>[Y]C(C)(C)c1ccsc1</smiles><smiles>CC(C)(C)c1cc2ccccc2o1</smiles>

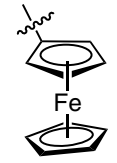

$\mathrm{R}^{1}=\mathrm{H}, \mathrm{Me}, \mathrm{Ph}$<smiles>O=C([Al])CPc1ccccc1</smiles><smiles></smiles>
$\mathrm{R}^{2}=\mathrm{H}, 2-\mathrm{Me}, 3-\mathrm{Me}, 2-\mathrm{NO}_{2}$<smiles>O=C1CCCCc2ccccc21</smiles>
$\mathrm{Ar}^{2}=$<smiles>CC(C)(C)c1cccc2ccccc12</smiles>
4-OEt, 4-i-Pr, 4-t-Bu, 4-F, 4-Cl, 4- $\mathrm{Br}$, 3-Br, 4- $\mathrm{CO}_{2} \mathrm{Me}$, 3- $\mathrm{CO}_{2} \mathrm{Me}$, 2-Ph<smiles>Cc1cccc2cccnc12</smiles><smiles>[Al]N/N=C(/CNc1ccccc1)c1ccccc1</smiles>

Significance: Reported is a remarkable synthesis of 1,4-disubstituted and 1,4,5-trisubstituted 1,2,3-triazoles. The reaction of readily available $\mathrm{N}$-tosylhydrazones with anilines is mediated by copper(II) and pivaloic acid. The reaction involves cyclization through $\mathrm{C}-\mathrm{N}$ and $\mathrm{N}-\mathrm{N}$ bond formation. This method enables an azide-free access to 1,2,3-triazoles with high efficiency under mild conditions. It exhibits a broad scope tolerating anilines with either electron-withdrawing or -donating groups and a variety of $\mathrm{N}$-tosylhydrazones. More significantly, the two-step synthesis starting from aryl ketones to the desired triazoles can also be executed in a one-pot fashion without compromising the yield. An exclusive high regioselectivity - 1,4-disubstituted or 1,4,5-trisubstituted products - constitutes another advantage of this method.

SYNFACTS Contributors: Victor Snieckus, Jun Xiao (Pfizer) Synfacts 2014, 10(1), 0019 Published online: 13.12.2013 Dol: 10.1055/s-0033-1340429; Reg-No.: V16013SF
Comment: The most common route to build 1,2,3-triazoles is through Huisgen-type [3+2] cycloadditions. Although numerous methods for the improvement of the Huisgen reaction were reported recently, it is inevitable that an azide (which may sometimes not be readily available) will be involved. To the best of our knowledge, this paper is the first report to synthesize 1,2,3-triazoles without using toxic and potential explosive azide species. A possible tosylhydrazone intermediate (see structure above) of the reaction was proposed and synthesized. Its subsequent treatment with a catalytic amount of copper resulted in the formation of the expected produc. Examples of utilizing heterocyclic amines (e.g., 3-aminopyridine) as substrates in this reaction may be anticipated. 


\section{Gategory}

Synthesis of

Heterocycles

\section{Key words}

palladium catalysis

carbonylative Heck reaction

arylfuranones

J. SCHRANCK, X.-F. WU, A. TLILI, H. NEUMANN, M. BELLER* (LEIBNIZ-INSTITUT FÜR KATALYSE E.V. AN DER UNIVERSITÄT ROSTOCK, GERMANY)

A Novel Double Carbonylation Reaction of Aryl Halides: Selective Synthesis of 5-Arylfuranones

Chem. Eur. J. 2013, 19, 12959-12964.

\section{Synthesis of 5-Arylfuranones via a Carbonylative Heck Reaction}

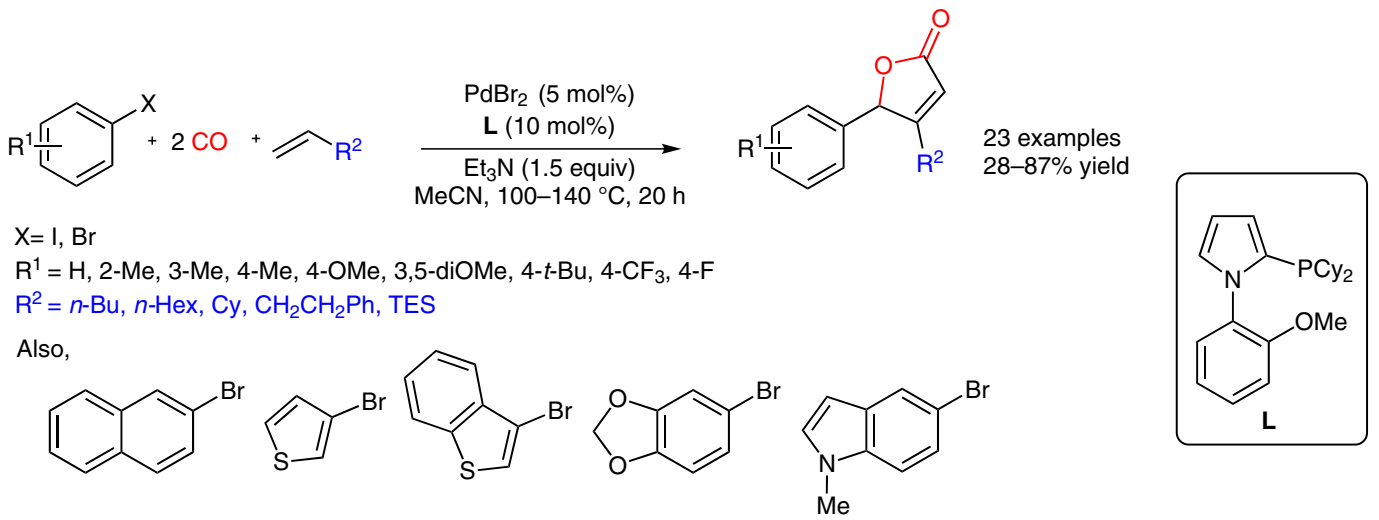

Significance: Reported is the synthesis of 5-arylfuranones by the three-component reaction of aryl halides, carbon monoxide, and alkenes in the presence of $\mathrm{PdBr}_{2}$, cataCXium POMeCy as ligand $\mathbf{L}$ and triethylamine as base. In the exploration of the scope of the reaction, substituted aryl bromides, aryl iodides, and different alkenes were tested. Aryl bromides bearing electron-donating groups $\left(\mathrm{R}^{1}=t\right.$-Bu, 3-OMe, 4-OMe) led to furanones in 55-77\% yield. However, aryl and alkyl bromides with electron-withdrawing groups, such as 4-bromoacetophenone, 4-bromoacetaldehyde and 4-bromobenzonitrile produced only trace amounts of products. Some bromo heterocycles including bromothiophene, bromobenzothiophene, benzodioxole, and indole derivatives were also tolerated. Terminal alkenes with $\mathrm{R}^{2}=n-\mathrm{Bu}$, Cy, TES afforded furanones in $54-73 \%$ yield, while an alkene with $\mathrm{R}^{2}=\mathrm{CH}_{2} \mathrm{CH}_{2} \mathrm{Ph}$ form the desired product in only $28 \%$ yield with a greater amount of the isomeric 3-alkyl-5-aryl-substituted furanone being formed.
Comment: Synthetic furanone compounds have been shown to inhibit bacterial quorum sensing in $P$. aeruginosa and to exhibit favorable therapeutic effects on $P$. aeruginosa lung infection $(\mathrm{H}$. Wu et al. J. Antimicrob. Chemother. 2004, 53, 1054). In the present double carbonylative Heck reaction, optimization of the reaction using different ligands, solvents, and the effect of carbon monoxide pressure was explored; increasing the carbon monoxide pressure from 5 to 20 bar resulted in improved yield. Use of inorganic base in the reaction failed to give furanone products. Similar reactivity was observed when aryl iodides were employed in place of aryl bromides. 


\section{Hydroarylation Approach to Phosphacoumarins}<smiles>[R]C#CP(=O)(O)Oc1cc[R7]cc1</smiles>

$\mathrm{Ph}_{3} \mathrm{PAuCl}(5 \mathrm{~mol} \%)$, AgOTf (5 mol\%), TfOH (3 equiv) DCE, r.t. to $80^{\circ} \mathrm{C}, 1-18 \mathrm{~h}$

$\mathrm{R}^{1}=\mathrm{Et}, \mathrm{Ph}$

$\mathrm{R}^{3}=\mathrm{H}, n-\mathrm{Bu}, \mathrm{Cl}\left(\mathrm{CH}_{2}\right)_{3}, \mathrm{Ph}, 4-\mathrm{ClC}_{6} \mathrm{H}_{4}, 4-\mathrm{BrC}_{6} \mathrm{H}_{4}, 4-\mathrm{MeOC}_{6} \mathrm{H}_{4}, 4-\mathrm{F}_{3} \mathrm{CC}_{6} \mathrm{H}_{4}$

Significance: Reported is an intramolecular hydroarylation of aryl alkynylphosphonates catalyzed by gold-silver and resulting in the formation of phosphacoumarins. The starting materials are synthesized by the reaction of terminal alkynes with chlorophosphonates using a strong base ( $n$-BuLi) at cryogenic temperatures. Optimization studies on the cyclization reaction using mixtures of different gold and silver salts led mostly to starting material recovery and/or isolation of $\beta$-ketophosphonates. Trifluoromethanesulfonic acid $(\mathrm{TfOH})$ as protic acid additive was unique in effecting the hydroarylation. Control experiments in the absence of gold, or in the absence of metals altogether, led to very poor yields of products. Surprisingly, no control experiment in the absence of silver was conducted. The substrate scope was well studied, except for absence of cases with $\mathrm{R}^{2}$ = electron-withdrawing groups. The yields seem to be consistently good.
Comment: Previous syntheses of phosphacoumarins, for example by the condensation of salicylaldehydes with diethylphosphonoacetates (C. H. Chen, J. L. Fox, J. L. Lippert J. Heterocycl. Chem. 1987, 24, 931) suffer from deficiencies such as poorly available starting materials and harsh reaction conditions. The current methodology offers usage of reasonably mild catalytic conditions and readily available starting materials. The synthesis of the starting chlorophosphonates, which is not reported, does not seem to be too arduous an undertaking. Mechanistic studies hint at the involvement of an allene intermediate. Refreshingly, the authors conclude that more mechanistic elucidation has to be performed rather than draw the unsupported catalytic cycle pervasive in the current literature. 


\section{Synthesis of}

Heterocycles

\section{Key words}

asymmetric organocatalysis

$\gamma$-lactams

$\delta$-lactams

$\delta$-lactones

radical reaction
S. VEllalATH, K. N. VAN, D. ROMO* (TEXAS A\&M UNIVERSity, COLlEGE STATION, USA) Direct Catalytic Asymmetric Synthesis of N-Heterocycles from Commodity Acid Chlorides by Employing $\alpha, \beta$-Unsaturated Acylammonium Salts Angew. Chem. Int. Ed. 2013, DOI: 10.1002/anie.201306050.

\section{Asymmetric Organocatalytic Synthesis of Lactams and Lactones}

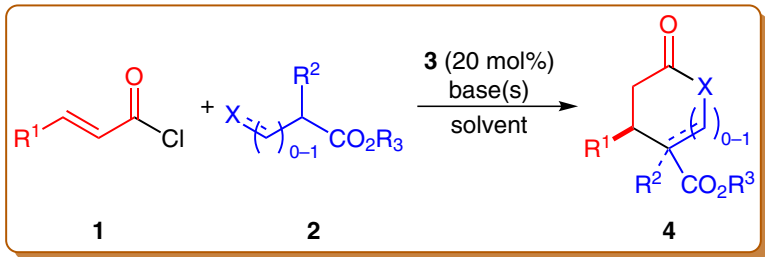

Selected examples: pyrrolidinones and piperidinones

catalyst: $\mathbf{3 b}$

bases:

LiHMDS (1 equiv)

DBU (1 equiv)

solvent: THF

conditions: $-30^{\circ} \mathrm{C}, 18 \mathrm{~h}$

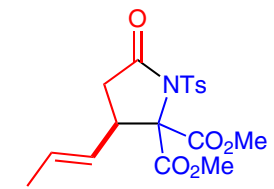

$80 \%$ yield, $93 \%$ ee used 2 equiv of $1,-10^{\circ} \mathrm{C}$

Selected examples: enol $\delta$-lactones

catalyst: $\mathbf{3 a}, \mathbf{3 c}$

bases:

LiHMDS (1 equiv)

DBU (1 equiv)

solvent: THF

conditions: $-30{ }^{\circ} \mathrm{C}, 18 \mathrm{~h}$

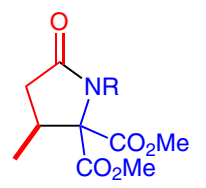

$\mathrm{R}=\mathrm{Bz} 78 \%$ yield, $86 \%$ ee (gram scale)

Ts $73 \%$ yield, $93 \%$ ee

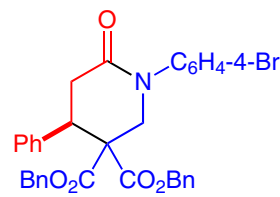

$40 \%$ yield, $93 \%$ ee used 2 equiv of $1,-15^{\circ} \mathrm{C}$

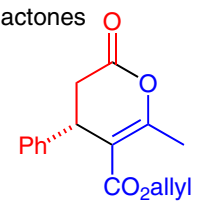

$52 \%$ yield, $90 \%$ ee catalyst $3 c$

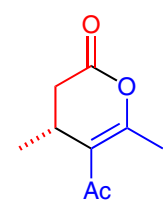

$48 \%$ yield, $89 \%$ ee catalyst $3 \mathrm{c}, 0^{\circ} \mathrm{C}$<smiles>C=CC1CC2CCN1CC2[C@H](OC)c1ccnc2ccc(OC)cc12</smiles><smiles>C=CC1CC2CN1CC2[C@H](OC)c1ccnc2ccc(OC)cc12</smiles>

3a $\mathbf{3 c}=(\mathrm{DHQ})_{2} \mathrm{PHAL}$

3b

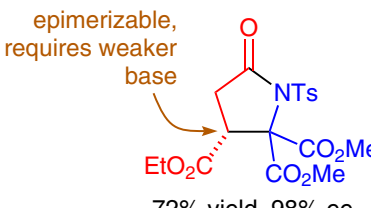

catalyst: $3 c$, bases: LiHMDS and DIPEA

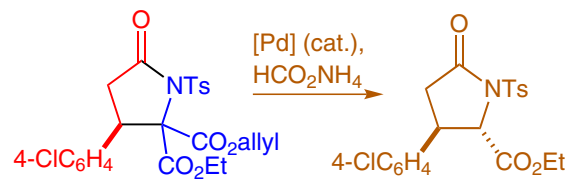

$74 \%$ yield,$-15{ }^{\circ} \mathrm{C} \quad 71 \%$ yield, $99 \%$ ee, $\mathrm{dr}=19: 1$ gram-scale synthesis of drug intermediate

Example: 3,4-dihydro-2-pyridinones

\section{catalyst $\mathbf{3 b}$}

base: DIPEA (3 equiv) additive: $\mathrm{LiCl}$ (1 equiv) $4 \AA$ MS

solvent: $\mathrm{PhMe}$

conditions: $23^{\circ} \mathrm{C}, 20 \mathrm{~h}$
Significance: The reported method for the synthesis of lactams and lactones $\mathbf{4}$ employs quinineand quinidine-derived catalysts 3 to activate $\alpha, \beta$ unsaturated acid chlorides $\mathbf{1}$ toward reaction with bisnucleophiles 2. A variety of heterocycles relevant to medicinal and natural product chemistry were obtained, including 2-pyrrolidinones, 2-piperidinones, enol $\delta$-valerolactones, and 3,4-dihydro-2-pyridinones. The yields are modest to good and enantioselectivity is good to excellent. The method was demonstrated to provide two intermediates for drug synthesis (one on a gram scale).

SYNFACTS Contributors: Victor Snieckus, Benjamin N. Rocke (Pfizer) Synfacts 2014, 10(1), 0022 Published online: 13.12.2013 DOI: 10.1055/s-0033-1340427; Reg-No.: V15813SF
Comment: For success of the reported method, significant tuning of the reaction conditions to the substrate, including the use of excess reactant; the choice of base, catalyst, and temperature; and the use of additives, is required. Catalyst $\mathbf{3} \mathbf{b}$ affords products of opposite configuration to those obtained using $\mathbf{3 a}$ or $\mathbf{3 c}$; although, in our opinion, the publication relies too heavily on assumptions in drawing this conclusion. In the synthesis of piperidinones, a retro-aza Michael side reaction results in low yields of the desired product. Interestingly, Michael addition, not acylation, appears to be the first mechanistic step, a fact essential to explaining the enantioselectivity. 
H. ZHANG, E. B. HAY, S. J. GEIB, D. P. CURRAN* (UNIVERSITY OF PITTSBURGH, USA)

Radical Cyclizations of Cyclic Ene Sulfonamides Occur with $\beta$-Elimination of Sulfonyl Radicals to Form Polycyclic Imines

J. Am. Chem. Soc. 2013, 135, 16610-16617.

\section{Polycyclic Imines via Radical Cyclization of Ene Sulfonamides}

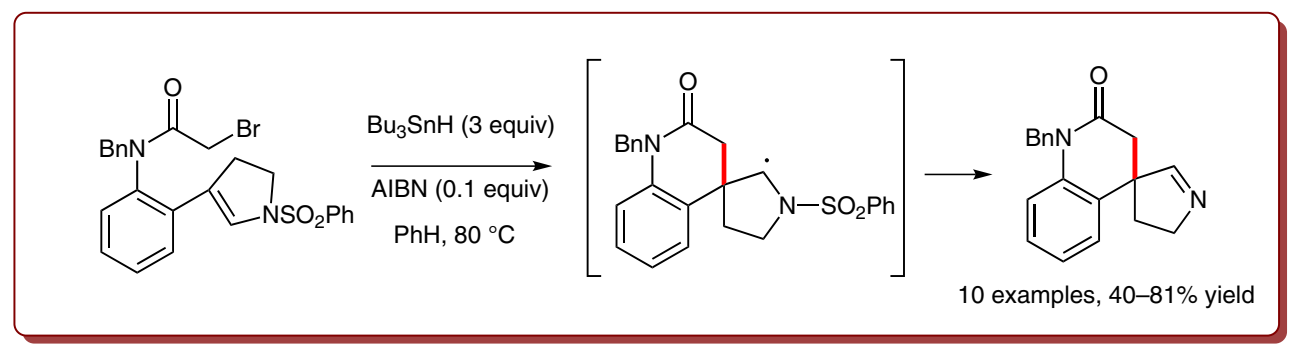<smiles>CC1(C)C(=O)Nc2ccccc2C12CCNC2</smiles>

$84 \%$ yield<smiles>O=C1CC2(C=NCCC2)c2ccccc2N1</smiles>

$73 \%$ yield<smiles>CC1(C)C(=O)Nc2ccccc2C12C=NCCC2</smiles>

$50 \%$ yield<smiles>CCC1=NCCCC12CC(=O)Nc1ccccc12</smiles>

$61 \%$ yield

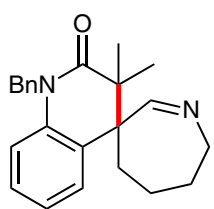

$40 \%$ yield

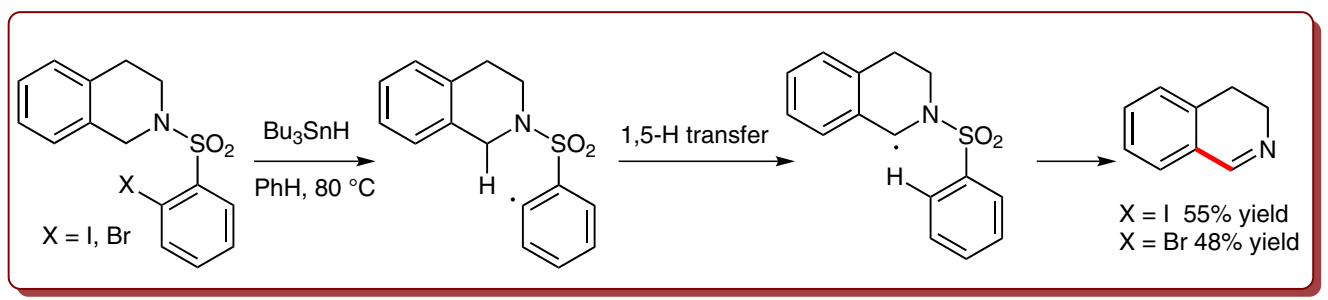

Significance: Reported is a radical cyclization of cyclic ene sulfonamides to give stable bicyclic and tricyclic imines in good yields. Mechanistically, an $\alpha$-sulfonamidoyl radical, which is generated after the initial radical cyclization, undergoes $\beta$-elimination to form the imine product and a phenylsulfonyl radical. In a related method, 3,4-dihydroquinolines can also be synthesized by radical translocation (1,5-hydrogen transfer) reactions of $\mathrm{N}$-(2-halophenylsulfonyl)tetrahydroisoquinolines. In both cases, the very stable sulfonamides are cleaved under mild reductive conditions.
Comment: Imines are highly versatile synthetic intermediates, which are commonly made by condensing the corresponding aldehydes and ketones with amines. The radical cyclization methodology described in this paper provides alternative bond construction and reaction conditions. It is also synthetically useful due to the facile cleavage of the strong $\mathrm{N}-\mathrm{SO}_{2} \mathrm{Ar}$ bond; these are hard to remove otherwise, for example, by hydrolysis or reduction.

\section{Key words}

polycyclic imines radical cyclization $\beta$-sulfonyl radical elimination 


\section{Gategory}

Synthesis of

Heterocycles

\section{Key words}

ruthenium catalysis

phosphaisocoumarins

C-H activation
Y. PARK, I. JEON, S. SHIN, J. MIN, P. H. LEE* (KANGWON NATIONAL UNIVERSITY, CHUNCHEON, REPUBLIC OF KOREA)

Ruthenium-Catalyzed C-H Activation/Cyclization for the Synthesis of Phosphaisocoumarins J. Org. Chem. 2013, 78, 10209-10220.

\section{Synthesis of Phosphaisocoumarins via Ruthenium Catalysis}

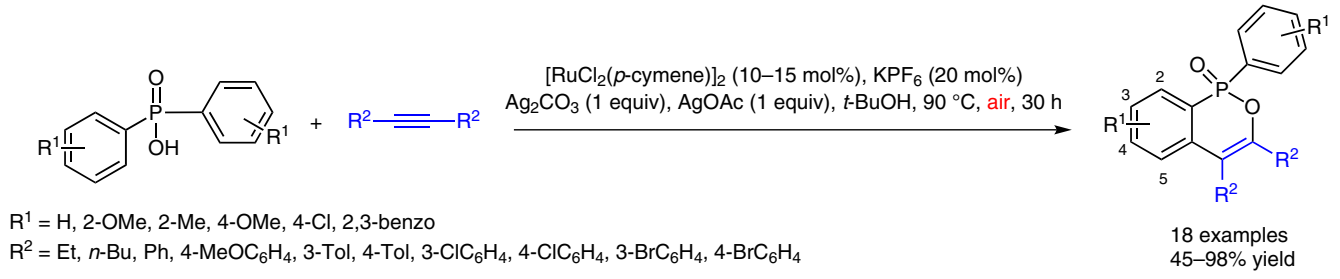

Significance: Presented is the ruthenium-catalyzed $\mathrm{C}-\mathrm{H}$ activation-cyclization of aryl phosphonic monoester and phosphinic acids resulting in phosphaisocoumarins. An extensive screening identified the witches' brew shown to be ideal. The reason for the effectiveness of the mixture of $\mathrm{Ag}_{2} \mathrm{CO}_{3}-\mathrm{AgOAc}-\mathrm{KPF}_{6}$ is not identified. However, it was shown that in the absence of $\mathrm{KPF}_{6}$ the reaction does proceed, albeit with lower yields (63\% vs. $97 \%$ ). AgOAc alone affords a comparable yield to the $\mathrm{Ag}_{2} \mathrm{CO}_{3}-\mathrm{AgOAc}$ mixture, although this was established early in the optimization study with only 2 mol\% ruthenium catalyst. AgOAc alone was not used with a higher catalyst loading, leading to the extrapolation that the reaction may be successful without additional $\mathrm{KPF}_{6}$ and $\mathrm{Ag}_{2} \mathrm{CO}_{3}$. The scope of the reaction was well studied and the yields range from moderate to good.
Comment: Heterocyclic phosphorus-containing compounds can have significant biological and pharmaceutical properties. The synthesis of phosphaisocoumarins has recently been reported using rhodium-catalyzed $\mathrm{C}-\mathrm{H}$ activation-cyclization of alkynes with organophosphorus compounds (Y. Unoh et al. Org. Lett. 2013, 15, 3258). The current report uses similar conditions, but with a less expensive ruthenium catalyst, albeit in a more complex overall reaction system. The reaction seems tolerant to electron-withdrawing and -donating groups on both alkyne and aryl phosphorus starting materials, although alkynes with strong electron-withdrawing groups were not tested. Some mechanistic studies were conducted using deuterium-labelled organophosphorus compounds, and a kinetic isotope effect $\left(k_{H} / k_{D}=5.67\right)$ was observed, indicating that $\mathrm{C} 2-\mathrm{H}$ bond cleavage is most likely involved in the rate-limiting step. A plausible mechanism was proposed, which does not include rationalization of the effect of the mixture of reagents involved in the reaction. 


\section{Three-Component Route for the Regioselective Construction of $\mathbf{N}$-Arylbenzimidazoles}

benzimidazoles

o-chloroaryl

sulfonates

o-chloroaryl halides

\section{anilines}

amides

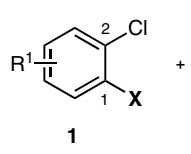

$$
+\mathrm{Ar}-\mathrm{NH}_{2}+\mathrm{R}^{2} \stackrel{\text { 少 }}{\mathrm{NH}_{2}} \stackrel{\begin{array}{c}
\text { catalyst }(2-6 \mathrm{~mol} \%) \\
\mathrm{Cs}_{2} \mathrm{CO}_{3}(2.4 \mathrm{equiv})
\end{array}}{t-\mathrm{BuOH}, 110^{\circ} \mathrm{C}, 12 \mathrm{~h}}
$$

$$
\text { (1 equiv) }
$$

(1.3 equiv)<smiles></smiles>

\section{8 examples}

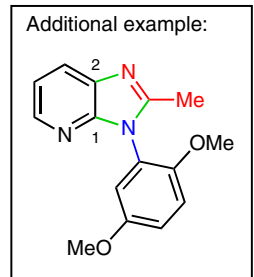

$\mathbf{X}=\mathrm{OTf}, \mathrm{Br}, \mathrm{C}$

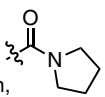

$\mathrm{R}^{1}=\mathrm{H}, 4-\mathrm{Me}, 5-\mathrm{Me}, 4-i-\mathrm{Pr}, 4-\mathrm{CF}_{3}$ 4-F, 4-OMe, 4-Ph, 5-CONHBn,

$\mathrm{R}^{2}=\mathrm{H}, \mathrm{Me}, \mathrm{Et}, c-\mathrm{Pr}, \mathrm{Cy}, \mathrm{CH}=\mathrm{CHMe}, \mathrm{Bn},(2-\mathrm{py}) \mathrm{CH}_{2}, \mathrm{Ph}, 3-\mathrm{F}_{3} \mathrm{CC}_{6} \mathrm{H}_{4}, 4-\mathrm{MeOC}_{6} \mathrm{H}_{4}$, thiophen-2-yl

$\mathrm{Ar}=3,5-\mathrm{Me}_{2} \mathrm{C}_{6} \mathrm{H}_{3}, 4-t-\mathrm{BuC}_{6} \mathrm{H}_{4}, 4-t-\mathrm{BuO}_{2} \mathrm{CC}_{6} \mathrm{H}_{4}, 4-\mathrm{F}_{3} \mathrm{CC}_{6} \mathrm{H}_{4}, 4-\mathrm{FC}_{6} \mathrm{H}_{4}, 2,4-\mathrm{F}_{2} \mathrm{C}_{6} \mathrm{H}_{3}, 2-\mathrm{MeOC}_{6} \mathrm{H}_{4}$

3-MeOC $\mathrm{H}_{4}, 4-\mathrm{MeOC}_{6} \mathrm{H}_{4}, 3-\mathrm{F}_{3} \mathrm{COC}_{6} \mathrm{H}_{4}, 4-\mathrm{F}_{3} \mathrm{COC}_{6} \mathrm{H}_{4}, 3,4-\left(\mathrm{OCH}_{2} \mathrm{O}\right) \mathrm{C}_{6} \mathrm{H}_{3}$, 3-py, 5-(2-MeOpy), z- $N$

$61 \%($ from $\mathrm{X}=\mathrm{Cl}$ )<smiles>COc1cccc(OC)c1</smiles>

$\mathrm{R}^{1}=i-\mathrm{Pr}, \mathrm{CF}_{3}, \mathrm{~F}, \mathrm{Ph}$ $\mathrm{R}^{2}=\mathrm{H}, \mathrm{Me}, \mathrm{C}-\mathrm{Pr}, \mathrm{Bn}$

$\mathrm{Ar}=2,4-\mathrm{F}_{2} \mathrm{C}_{6} \mathrm{H}_{3}, 3-\mathrm{F}_{3} \mathrm{COC}_{6} \mathrm{H}_{4}, 3,4-\left(\mathrm{OCH}_{2} \mathrm{O}\right) \mathrm{C}_{6} \mathrm{H}_{3}, 3-\mathrm{py}$

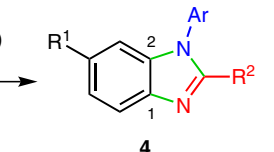

4

4 examples $64-81 \%$ yield

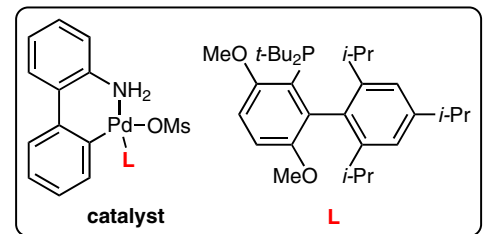

palladium catalysis

Significance: Reported is a regiocontrolled synthesis of $\mathbf{N}$-arylbenzimidazoles $\mathbf{3}$ and $\mathbf{4}$ via a threecomponent reaction using a palladium catalyst. In this reaction, the 2-chloroarenes $\mathbf{1}$ and $\mathbf{2}$ show different reactivities in combining with anilines and amides in sequential intermolecular amination and amidation reactions and cyclizations to regioselectively afford two types of $N$-arylbenzimidazoles, $\mathbf{3}$ and $\mathbf{4}$, in moderate to good yields. The reaction scope and limitations for the 2-chloroarenes 2 were not well investigated.
Comment: Benzimidazoles are often found in nature and in drugs displaying broad spectrum pharmaceutical activities (see Review below). Poor regiocontrolled benzimidazole arylations to give mixtures of isomeric products have been previously reported (e.g., D. Yang et al. J. Org. Chem. 2008, 73, 7841). The present method not only assembles the substituted benzimidazoles in a straightforward way from readily available starting materials, but also offers a high regiocontrol in the construction of single isomer products.

Review: F. Fei, Z. Zhuo Expert Opin. Ther. Patents 2013, 23, 1157-1179. 


\section{Gategory}

\section{Synthesis of}

Heterocycles

\section{Key words}

spirocycles

oxindoles

Ullmann coupling

Claisen

rearrangement
H. MIYAMOTO, T. HIRANO, Y. OKAWA, A. NAKAZAKI, * S. KOBAYASHI* (TOKYO UNIVERSITY OF SCIENCE, CHIBA, JAPAN)

Stereoselective Synthesis of Spirocyclic Oxindoles Based on a One-Pot Ullmann Coupling/Claisen Rearrangement and its Application to the Synthesis of a Hexahydropyrrolo[2,3- $b$ ]indole Alkaloid Tetrahedron 2013, 69, 9481-9493.

\section{Construction of Spirocyclic Oxindoles for Indole Alkaloid Synthesis}

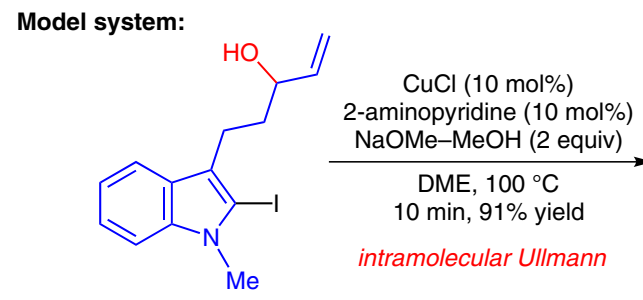

Application to total synthesis:

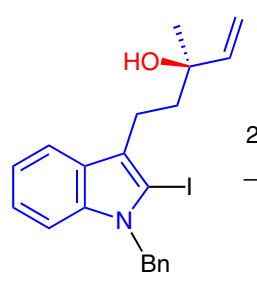

(R) $97 \%$ ee

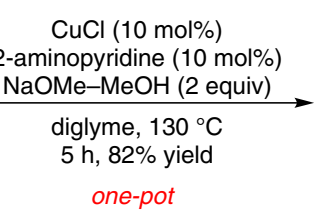

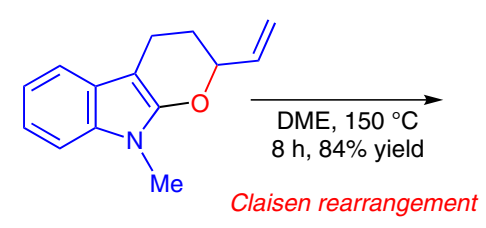
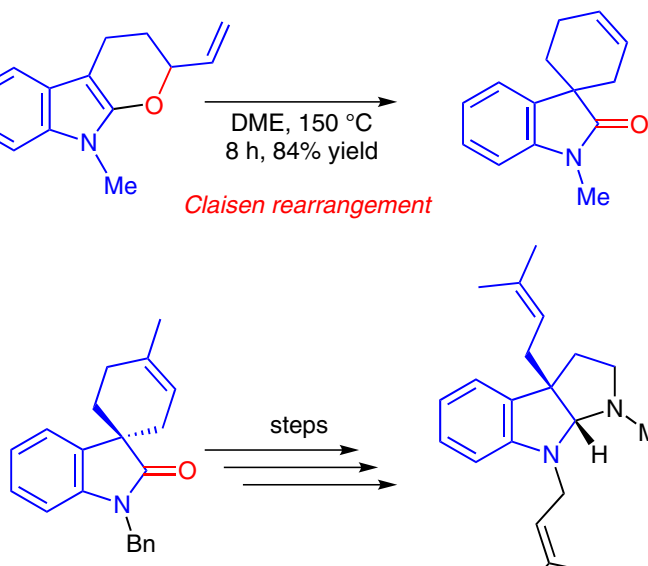

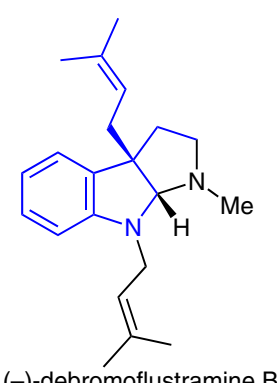

(-)-debromoflustramine B
(S) $95 \%$ ee
Significance: Oxindoles bearing a quaternary stereogenic center at C3 represent attractive synthetic targets due to both their biological activity and their utility as synthetic intermediates. Kobayashi and co-workers have previously reported a stereoselective Claisen rearrangement of bicyclic dihydropyrans to provide multifunctionalized spiro[4.5]decanes (see Review below). The current study extends this methodology to the rearrangement of pyranoindoles, which are accessed from readily synthesized 2-haloindoles through an intramolecular Ullmann condensation (IUC), to yield spirocyclic oxindoles in a stereoselective manner. Oxidative cleavage of the olefin moiety of the products leads to stereochemically defined oxindoles, which can be readily elaborated into members of the hexahydropyrrolo[2,3b]indole family of alkaloids, as demonstrated by the synthesis of (-)-debromoflustramine B.

Review: A. Nakazakia, S. Kobayashi Synlett 2012 23, 1427-1445.

SYNFACTS Contributors: Victor Snieckus, Paul Richardson (Pfizer) Synfacts 2014, 10(1), 0026 Published online: 13.12.2013 Dol: 10.1055/s-0033-1340424; Reg-No.: V15513SF
Comment: Optimization studies demonstrated that the IUC proceeded best under modified Hauptman coupling conditions ( $\mathrm{CuCl}$, 2-aminopyridine, $\mathrm{NaOMe}$ ). The Claisen rearrangement occurred simply by heating the intermediate pyranoindoles. Due to issues with the stability of the intermediates, a one-pot sequence was developed in which, on completion of the IUC, the temperature was raised to effect the rearrangement. Indoles incorporating trans substituents on the allylic alcohol afforded the oxindole as single diastereomers (NOE, X-ray analyses), the stereochemistry of which indicated that the rearrangement proceeds through a boat-like transition state. The cis isomers did not give the desired products, and attempts to form furanoindoles also failed. A range of $\mathrm{N}$-indole protecting groups were tolerated. A remarkable rate enhancement was observed running the reaction in glyme solvents, which avoided the use of a sealed tube. Subjecting enantiopure secondary alcohols to the reaction led to a slight erosion in enantiomeric excess (10-15\% ee), whereas the ee of chiral tertiary alcohols was maintained. 


\section{Aza-Morita-Baylis-Hillman Synthesis of Benzoxazepines}

Gategory

Synthesis of

Heterocycles

Key words

benzoxazepines

aza-Morita-BaylisHillman reaction

triphenylphosphine<smiles>Cc1ccc(S(=O)(=O)/N=C/c2ccncc2O)cc1</smiles><smiles>CC=C=CC(=O)O</smiles>

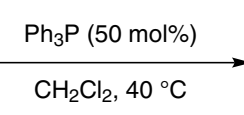

$\mathrm{R}^{1}=5-\mathrm{Br}, 5-\mathrm{Cl}, 3-\mathrm{Cl}, \mathrm{H}, 5-\mathrm{Me}, 5-\mathrm{t}-\mathrm{Bu}, 5-\mathrm{OMe}$ $\mathrm{R}^{2}=\mathrm{Me}, \mathrm{Et}, \mathrm{Bn}$

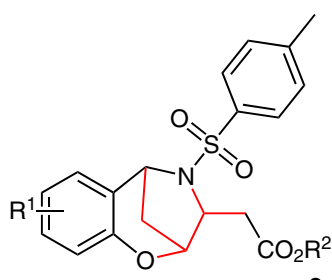

$0-71 \%$ yield
Significance: The benzoxazepine skeleton is present in compounds with important anticonvulsant, antipsychotic, and cytotoxic properties. Methods for the preparation of benzoxazepines involve either $\mathrm{C}-\mathrm{C}$ or $\mathrm{C}-\mathrm{N}$ ring closure, some of them using transition-metal catalysis (M. Rueping, A. Kuenkel, R. Fröhlich Chem. Eur. J. 2010, 16, 4173). Since removal of residual metallic impurities from pharmaceutical products is difficult and increases the final cost, it is important to develop metal-free reactions. Reported is a triphenylphosphine-catalyzed reaction of salicyl $N$-tosylimines with allene esters to synthesize benzoxazepine derivatives. The allenoates were easily obtained by Wittig reaction of the propanoyl chloride and alkoxy or benzyloxy carbonylmethylene-triphenylphosphorane, to avoid the use of expensive commercially available allenes.
Comment: The reported reaction was weakly explored in terms of scope of substituted salicyl $\mathrm{N}$-tosylimines. The electron-donating methyl and tert-butyl groups clearly decreased the reaction yields and methoxy groups prevented the reaction from occurring. When $\mathrm{R}^{2}$ was changed to a $t$-Bu group, compound $\mathbf{4}$ was obtained in 69\% yield instead of the expected benzoxazepine. Interestingly, this structural skeleton is also the final intermediate in the proposed mechanism, prior to a Michael addition of the $N$-tosyl-protected nitrogen on the double bond. Whether this means that the proposed mechanism is correct or not, is unclear, as more mechanistic evidence was not offered. 